\title{
Effect of Acute Sodium Bicarbonate Intake on Sprint-Intermittent Performance and Blood Biochemical Responses in Well-Trained Sprinters
}

\author{
Mohammad Fayiz AbuMoh'd', Walid Alsababha', Yazan Haddad², Ghaid Obeidat', Yaser Telfah² \\ Affiliations: 'Yarmouk University, Faculty of Physical Education, Department of Sports/Movement Sciences, Irbid, Jordan, ${ }^{2}$ Yarmouk University, \\ Faculty of Physical Education, Department of Physical Education, Irbid, Jordan
}

Correspondence: M. F. AbuMoh'd, Yarmouk University, Faculty of Physical Education, Department of Sports/Movement Sciences, University St., Irbid, Jordan. E-mail: famohammad@yu.edu.jo

\begin{abstract}
The present study was designed to determine the acute effect of sodium bicarbonate $\left(\mathrm{NaHCO}_{3}\right)$ on the number of sprint repetitions during sprint high-intensity intermittent testing. In addition, blood biochemical ( $\mathrm{pH}$, $\mathrm{HCO}_{3}{ }^{-}$, and lactate) responses measured in three occasions were investigated. Thirteen male well-trained sprinters ( $24.65 \pm 3.44 \mathrm{yrs}$ ) performed two consecutive trials (7 days apart). Athletes were assigned randomly either to ingest a single dose of $\mathrm{NaHCO}_{3}(0.3 \mathrm{~g} / \mathrm{kg}) 1 \mathrm{~h}$ prior to exercise or placebo using a double-blind crossover design. The intermittent sprint test consisted of $60 \mathrm{~s}$ treadmill sprints ( $90 \%$ of maximal work done) and $30-\mathrm{s}$ recovery repeated intermittently until volitional exhaustion. Blood samples were collected from all athletes before exercise, after $1 \mathrm{~h}$ of dose intake, and after exercise in each trial. Paired sample t-testing showed that athletes complete significantly more sprint repetitions $(p=0.036)$ during the intermittent sprint test with $\mathrm{NaHCO}_{3}(6.846 \pm 3.114)$ than with the placebo (5.538 \pm 3.872$)$. Data also revealed no differences between trials in all blood responses at pre-exercise. After $1 \mathrm{~h}$ of dose consumption, however, blood $\mathrm{pH}$ and $\mathrm{HCO}_{3}{ }^{-}$were higher with $\mathrm{NaHCO}_{3}$ than with placebo $(\mathrm{p}<0.05)$, but no differences were noted in lactate between trials ( $p>0.05)$. After completion of the test, all blood responses were significantly higher with $\mathrm{NaHCO}_{3}$ than with placebo $(p<0.05)$. In conclusion, intake of $0.3 \mathrm{~g} / \mathrm{kg}$ of $\mathrm{NaHCO}_{3} 1 \mathrm{~h}$ prior to treadmill sprint-intermittent performance increased sprint repetitions in well-trained sprinters, probably due to activated glycolysis caused by intracellular protons efflux into the blood.
\end{abstract}

Keywords: glycolytic enzymes, blood pH, buffering capacity, contractile force, fatigue

$@$ @JSSMontenegro

EFFECT OF $\mathrm{NaHCO}_{3}$ ON SPRINT-INTERMITTENT EXERCISE

http://mjssm.me/?sekcija=article\&artid=206

Cite this article: AbuMoh'd, M.F., Alsababha, W., Haddad, Y., Obeidat, G., \& Telfah, Y. (2021). Effect of Acute Sodium Bicarbonate Intake on Sprint-Intermittent Performance and Blood Biochemical Responses in Well-Trained Sprinters. Montenegrin Journal of Sports Science and Medicine, 10 (1), 5-10. doi: 10.26773/mjssm.210301

\section{Introduction}

High-intensity intermittent exercise results in a pronounced accumulation of glycolytic metabolites as a consequence of anaerobic energy delivery in the working muscles (da Silva et al., 2019; Danaher, Gerber, Wellard, \& Stathis, 2014; Coso, Hamouti, Agudo-Jimenez, \& Mora-Rodriguez, 2010; Sweeney, Wright, Brice, \& Doberstein, 2010). As exercise progresses, the production of hydrogen cations $\left(\mathrm{H}^{+}\right)$increas- 
es (Saunders et al., 2017) and the pH of the muscle declines (Hobson, Saunders, Ball, Harris, \& Sale, 2012), which leads to acid-base imbalance. Increased acidity of the working muscles caused by $\mathrm{H}^{+}$accumulation is a major cause of fatigue (Debold, Fitts, Sundberg, \& Nosek, 2016; Fitts, 2016; Bishop, Edge, Davis, \& Goodman, 2004) and can lead to performance impairments when exercise is performed at high intensities (de Salles Painelli et al., 2013; Tobias et al., 2013; Robergs, Hutchinson, Hendee, Madden, \& Siegler, 2005). More specifically, muscle acidosis has been shown to impair energy transfer via the anaerobic system (da Silva et al., 2019), disrupt phosphorylcreatine (PCr) resynthesis (Sahlin, Harris, \& Hultman, 1975), and to inhibit the activity of key glycolytic enzymes, such as glycogen phosphorylase and phosphofructokinase (da Silva et al., 2019). Subsequently, the ability of the muscles to cope with high-energy demands decreases (Gladden, 2004).

Although a great portion of the contraction-induced $\mathrm{H}^{+}$ is rapidly transported out of the working myocytes to blood and buffered by bicarbonate $\left(\mathrm{HCO}_{3}{ }^{-}\right.$) (de Salles Painelli et al., 2013; Requena, Zabala, Padial, \& Feriche, 2005), blood acidosis could also contribute to fatigue indirectly during high-intensity exercise (Price, Moss, \& Prance, 2003; Hobson et al. 2012). In this context, nutritional supplements have been shown to attenuate acidosis and delay fatigue; sodium bicarbonate $\left(\mathrm{NaHCO}_{3}\right)$ is one of them.

$\mathrm{NaHCO}_{3}$ is the most frequently alkalotic agent used by athletes who reliance on glycolysis to delay fatigue (da Silva et al., 2019; Saunders et al. 2017) and reduce ratings of perceived exertion (RPE) (Carr, Slater, Gore, Dawson, \& Burke, 2011). $\mathrm{NaHCO}_{3}$ can increase the extracellular buffering capacity by increasing blood $\mathrm{HCO}_{3}{ }^{-}$concentration (de Salles Painelli et al., 2013; Oliveira et al., 2017) in which it enhances $\mathrm{H}^{+}$efflux from the working muscles to the blood (da Silva et al., 2019; de Salles Painelli et al., 2013) where they are neutralized (Bishop et al., 2004).

Several investigations have shown that increased circulation-buffering capacity, achieved either by acute (single dose) or chronic (supplementation) $\mathrm{NaHCO}_{3}$ intake, improves performance and capacity at high intensities (Carr et al., 2011; Requena et al., 2005; Tobias et al., 2013; Lancha Junior, de Salles Painelli, Saunders, \& Artioli, 2015). This indicates that NaH$\mathrm{CO}_{3}$ has been reported to be beneficial in events with high-intensity exercise lasting from approximately 1 to 5 minutes (Carr et al., 2011; Saunders et al., 2017; Tobias et al., 2013), with utilized dose ranging from 0.1 to $0.5 \mathrm{~g} / \mathrm{kg}$ body mass (McNaughton, Backx, Palmer, \& Strange, 1999). The mechanism proposed to be reasonable for the effect of $\mathrm{NaHCO}_{3}$ involves increased activation of the glycolytic and the adenosine triphosphate (ATP)-PCr systems (Deb, Gough, Sparks, \& McNaughton, 2018), although elevation in blood lactate has been demonstrated following $\mathrm{NaHCO}_{3}$ intake (Artioli et al., 2007).

Studies using repeated sprint bouts of high-intensity exercise have observed performance improvement (Price et al., 2003; Bishop et al., 2004; Tobias et al., 2013; Deb et al., 2018), but others failed to report beneficial effects (de Araujo Dias et al., 2015; de Salles Painelli et al., 2013; da Silva et al., 2019). Beside of discrepancies associated with the beneficial effect of $\mathrm{NaHCO}_{3}$, high volume and intensity exercise could induce acid-base disturbances (Carr et al., 2013). Additionally, although $\mathrm{NaHCO}_{3}$ has been studied for years, most investigations have been conducted using cycling ergometer tests. However, the effect of $\mathrm{NaHCO}_{3}$ intake on blood responses during repeated sprint-intermittent testing on a treadmill remains poorly investigated, and its effect on exercise capacity has yet to be demonstrated. Therefore, this study aimed to determine the number of sprint repetitions during treadmill high-intensity intermittent exercise protocol until volitional exhaustion. A secondary aim of this study was to investigate the concentrations of blood $\mathrm{pH}$, $\mathrm{HCO}_{3}{ }^{-}$, and lactate in response to exercise. We hypothesized that extracellular buffering capacity by ingesting acute $\mathrm{NaH}$ $\mathrm{CO}_{3}$ might attenuate blood acidity and improve performance.

\section{Methods}

\section{Participants}

Thirteen male well-trained sprinting athletes (see Table 1 for participants demographic data) volunteered to participate in the present study, following being informed about the potential risks and benefits involved in participation. All athletes had been involved in a sprinting training at the Jordan Military Sports Federation for a minimum of five years. Other inclusion criteria for participation were the following: long male athletes; age ranged 20-30 years old; no previous injuries for at least four months, and not consuming $\mathrm{NaHCO}_{3}$ or any ergogenic aids seven days prior to participation. This study was approved in advance by the local scientific research committee of Yarmouk University (protocol. 11-2019 M.A). Each participant voluntarily provided written informed consent before participation.

Table 1. Participants' demographic data

\begin{tabular}{cc}
\hline Variables & Mean \pm SD \\
\hline Age (years) & $24.65 \pm 3.44$ \\
Height $(\mathrm{cm})$ & $181.55 \pm 4.74$ \\
Mass $(\mathrm{kg})$ & $79.34 \pm 5.22$ \\
BMI $\left(\mathrm{kg} / \mathrm{m}^{2}\right)$ & $24.30 \pm 2.46$ \\
resting HR (bpm) & $63.67 \pm 3.92$ \\
Training volume (min/week) & $420.33 \pm 48.61$ \\
Training experience (years) & $6.23 \pm 1.98$ \\
100-m best time (s) & $10.43 \pm 0.60$ \\
\hline
\end{tabular}

\section{Experimental design}

Athletes performed two experimental trials in which they ingested a single dose of $\mathrm{NaHCO}_{3}$ (Premium sodium bicarbonate powder, VITADIRECT, USA) or maltodextrin (placebo). The trials were randomized and separated by one week to complete recovery, with both trials performed at the same time of the day $(07.45 \mathrm{AM})$ to ensure that the findings were not affected by circadian rhythm. $\mathrm{NaHCO}_{3}$ and placebo were coded before data collection. The doses were administered in a crossover design, with the double-blind provision of $\mathrm{NaHCO}_{3}$ and placebo, as neither examiners nor athletes were aware of the experimental treatment. Each trial consisted of 1) intake 
of $\mathrm{NaHCO}_{3}$ or placebo in the laboratory one hour prior to exercise, 2) a standardized 10-min warm-up (treadmill jogging with a speed of $7-8 \mathrm{~km} / \mathrm{h}$, joint mobilization, and stretching), and 3) repeated intermittent sprint test on a treadmill. Athletes were instructed to refrain from drinking water during the trial. The exercise protocol in both trials was performed in a cool environment $\left(20-22^{\circ} \mathrm{C}\right)$ and $42-45 \%$ relative humidity.

\section{Experimental procedure}

Each athlete visited the laboratory on four different occasions. Athletes' characteristics and vital factors were measured on the first visit. On the second visit, each athlete engaged in a warm-up to prepare themselves for running on a treadmill (Technogym Excite + RUN 1000-19" LED Touchscreen, Italy). They engaged in running three bouts with different speeds that ranged from low to moderate $(7-13 \mathrm{~km} / \mathrm{h})$ for $10 \mathrm{~min}$. On the next day (third visit), each athlete was familiarized with running on the treadmill for $15 \mathrm{~min}$. After a $5 \mathrm{~min}$ rest, the athletes underwent a graded exercise test to determine $\mathrm{VO}_{2 \max }$, in which exercise intensity is progressively increased while measuring ventilation and oxygen and carbon dioxide concentration of the inhaled and exhaled air. $\mathrm{VO}_{2 \max }$ is reached when oxygen consumption remains at a steady state despite an increase in workload (see Price et al., 2003). This regimen was done to measure the athletes' greater speed (intensity) associated with $\mathrm{VO}_{2 \max }$ while performing in each trial for a $60 \mathrm{~s}$ sprint. Determination of $V \mathrm{O}_{2 \max }$ was to know the efficacy of cardiopulmonary status and to indicate a preparedness of athletes' ability to perform the intermittent sprint test effectively. The results of athletes' $\mathrm{VO}_{2 \max }$ and greater treadmill speed were $59.36 \pm 3.61 \mathrm{ml} / \mathrm{kg} / \mathrm{min} ; 17.05 \pm 1.71$ $\mathrm{km} / \mathrm{h}$, respectively.

On the fourth visit, we repeated the regimen for each athlete to confirm the intensity (speed) of the exercise. Test-retest showed no difference in $V \mathrm{O}_{\max }(\mathrm{t}=2.14, \mathrm{p}=0.32)$ and maximal speed $(\mathrm{t}=0.65, \mathrm{p}=0.73)$. Athletes then asked to perform the intermittent sprint test at a speed of $90 \%$ of their achieved maximal speed (range: 16.6-17.5 km/h). The tests were measured over three days.

All athletes were instructed to refrain from strenuous exercise in the 48 hours prior to each trial and also abstaining from drinking coffee for 12 hours. They were asked to avoid breakfast (eating) before beginning a trial to limit confounding nutritional effect on performance and to ensure $\mathrm{NaHCO}_{3}$ absorption. Each athlete was asked to drink $500 \mathrm{ml}$ of water 90 min prior to each trial to prevent possible dehydration.

\section{$\mathrm{NaHCO}_{3}$ and placebo intake protocol}

Athletes were instructed to ingest $0.3 \mathrm{~g} / \mathrm{kg}$ of $\mathrm{NaHCO}_{3}$ orally $1 \mathrm{~h}$ prior to the experimental trial. $\mathrm{NaHCO}_{3}$ was administered in $400 \mathrm{ml}$ of chilled water $\left(16^{\circ} \mathrm{C}\right)$ and mixed with $30 \mathrm{ml}$ of strawberry flavour. The selected dose was used to avoid possible confounding factors that may impede performance. An intake acute dose of $\mathrm{NaHCO}_{3}$ greater than $0.5 \mathrm{~g} / \mathrm{kg}$ body mass can cause abdominal pain, flatulence, nausea, vomiting, and diarrhoea (Lancha Junior et al., 2015). In addition, all athletes were requested to ingest the supplement within 10 minutes to optimal absorption (Deb et al., 2018). In the placebo trial, athletes were asked to complete the same order with maltodextrin. The supplements were ingested using indistinguishable bottles so that the participants did not know which drink they had ingested.

\section{Sprint-intermittent test}

The intermittent sprint test consisted of treadmill repeated 60-s sprint bouts until volitional exhaustion (task failure). Rest periods were 30 s between bouts. A speed of $16.6-17.5 \mathrm{~km} / \mathrm{h}$ (the range of athletes' maximal speed) was maintained in the treadmill throughout the bouts, in which the athletes were encouraged to complete as many as possible repetitions successfully. Task failure defined as the inability to maintain sprinting within 10 seconds of the preferred cadence.

\section{Blood samples collection and analysis}

The blood samples were collected from each participant in both trials to measure blood $\mathrm{pH}, \mathrm{HCO}_{3}{ }^{-}$, and lactate on three occasions: pre-exercise, post- $1 \mathrm{~h}$ of dose intake, and post-exercise. Venipuncture was used to obtain blood samples (4 ml). Blood $\mathrm{pH}$ and $\mathrm{HCO}_{3}{ }^{-}$were analysed using an ABL800 radiometer (Denmark). Blood lactate concentration was analysed using an Integral 400 device (Switzerland). The reference ranges of variables were as follows: $0.63-2.44 \mathrm{mmol} / \mathrm{L}$ for lactate, 22.0-29.0 mmol/ $/ \mathrm{L}_{\text {for }} \mathrm{HCO}_{3}{ }^{-}$. The normal blood $\mathrm{pH}$ is tightly regulated between 7.35 and 7.45 .

\section{Statistical analysis}

The Shapiro-Wilk test was applied to check for normal distribution. All variables (blood $\mathrm{pH}, \mathrm{HCO}_{3}{ }^{-}$, and lactate) at the three time points were normally distributed $(\mathrm{p}>0.05)$. A repeated measures analysis of variance (ANOVA) with a Greenhouse-Geisser correction was used to determine possible differences in blood responses at the three time points within a trial. When a significant $F$ rate was achieved, a post hoc test using the Bonferroni correction was used for pairwise comparison using adjusted means. A paired sample t-test was used to analyse the differences in the number of sprint repetitions between trials, and to analyse the differences in each measured point between trials. Frequentist inferences were assessed against the mean difference $\pm 95 \%$ confidence interval CI between trials in which that variances do not cross the zero-boundary interpreted as significant. All descriptive data are reported as mean \pm SD. Significance was set at $\mathrm{P}<0.05$ for all analyses. Statistical analysis was conducted using SPSS version 18.0 and Microsoft Excel.

\section{Results}

Data revealed that the number of sprint repetitions during the intermittent sprint test were significantly greater with $\mathrm{NaHCO}_{3}(6.846 \pm 3.114)$ than with the placebo $(5.538 \pm 3.872)$ $(\mathrm{t}=4.113, \mathrm{p}=0.036)$. Table 2 illustrates the results of blood biochemical responses to the $\mathrm{NaHCO}_{3}$ at three time points: 1) pre-exercise, 2) $1 \mathrm{~h}$ after dose intake, and 3) post-exercise. The analysed data showed statistical differences in all blood responses. Post hoc using Bonferroni with adjusted means revealed that both blood $\mathrm{pH}$ and $\mathrm{HCO}_{3}{ }^{-}$were significantly higher after $1 \mathrm{~h}$ of $\mathrm{NaHCO}_{3}$ intake compared to pre- $(\mathrm{F}=4.201$, $\mathrm{p}=0.027 ; \mathrm{F}=3.817, \mathrm{p}=0.030$ for $\mathrm{pH}$ and $\mathrm{HCO}_{3}{ }^{-}$, respectively) and post-exercise $(\mathrm{F}=3.522, \mathrm{p}=0.034 ; \mathrm{F}=2.961, \mathrm{p}=0.041$ for $\mathrm{pH}$ and $\mathrm{HCO}_{3}{ }^{-}$, respectively), whereas blood lactate level was elevated after the finish of the test in comparison to the pre-exercise level $(\mathrm{F}=6.012, \mathrm{p}=0.003)$ and $1 \mathrm{~h}$ post-dose $(\mathrm{F}=8.976, \mathrm{p}=0.001)$, with no differences between pre-exercise and $1 \mathrm{~h}$ post-dose $(\mathrm{F}=0.351, \mathrm{p}=0.468)$.

Table 3 illustrates the results of blood biochemical responses to the placebo at the same three time points. Data showed differences in all blood responses. Post hoc using Bonferroni with 
Table 2. Results of blood biochemical responses to $\mathrm{NaHCO}_{3}$ at baseline (pre-exercise), $1 \mathrm{~h}$ after ingestion, and at after exercise in 13 well-trained sprinters. Data were analysed using one-way ANOVA

\begin{tabular}{cccc}
\hline Parameters & Pre-exercise & 1-h post dose & Post-exercise \\
\hline $\mathrm{pH}$ & $7.42 \pm 0.03$ & $7.47 \pm 0.02^{\mathrm{a}}$ & $7.37 \pm 0.05^{\mathrm{a}, \mathrm{b}}$ \\
$\mathrm{HCO}^{-}{ }^{-}(\mathrm{mmol} / \mathrm{L})$ & $25.81 \pm 2.44$ & $30.63 \pm 4.01^{\mathrm{a}}$ & $17.28 \pm 4.16^{\mathrm{a}, \mathrm{b}}$ \\
Lactate $(\mathrm{mmol} / \mathrm{L})$ & $1.95 \pm 1.88$ & $2.21 \pm 0.24$ & $13.11 \pm 3.09^{\mathrm{a}, \mathrm{b}}$ \\
\hline
\end{tabular}

Note. Significance level was set at $\mathrm{p}<0.05$; Values expressed as mean $\pm \mathrm{SD}$; a Significantly different than pre-exercise; ${ }^{\text {b Significantly }}$ different than $1 \mathrm{~h}$ post-dose.

adjusted means revealed that both blood $\mathrm{pH}$ and $\mathrm{HCO}_{3}{ }^{-}$were higher after $1 \mathrm{~h}$ of placebo intake compared to pre- $(\mathrm{F}=5.101$, $\mathrm{p}=0.021 ; \mathrm{F}=4.748, \mathrm{p}=0.019$ for $\mathrm{pH}$ and $\mathrm{HCO}_{3}{ }^{-}$, respectively) and post-exercise $(\mathrm{F}=2.676, \mathrm{p}=0.044 ; \mathrm{F}=2.11, \mathrm{p}=0.048$ for $\mathrm{pH}$ and $\mathrm{HCO}_{3}{ }^{-}$, respectively), with no differences between pre-exercise and $1 \mathrm{~h}$ post dose $(\mathrm{F}=0.589, \mathrm{p}=0.337 ; \mathrm{F}=0.343, \mathrm{p}=0.401)$. After the finish of the test, the blood lactate level was increased over the post-exercise level than pre-exercise $(\mathrm{F}=5.396, \mathrm{p}=0.004)$ and $1 \mathrm{~h}$ post-dose $(\mathrm{F}=5.091, \mathrm{p}=0.003)$, with no differences between pre-exercise and $1 \mathrm{~h}$ post-dose $(\mathrm{F}=0.286, \mathrm{p}=0.573)$.

Table 3. Results of blood biochemical responses to placebo at baseline (pre-exercise), $1 \mathrm{~h}$ after ingestion, and at after exercise in 13 well-trained sprinters. Data were analysed using one-way ANOVA

\begin{tabular}{cccc}
\hline Parameters & Pre-exercise & 1-h post dose & Post-exercise \\
\hline $\mathrm{pH}$ & $7.43 \pm 0.02$ & $7.43 \pm 0.02$ & $7.29 \pm 0.04^{\mathrm{a}, \mathrm{b}}$ \\
$\mathrm{HCO}^{-}{ }^{-}(\mathrm{mmol} / \mathrm{L})$ & $25.74 \pm 2.74$ & $25.59 \pm 3.22$ & $14.56 \pm 4.38^{\mathrm{a}, \mathrm{b}}$ \\
Lactate $(\mathrm{mmol} / \mathrm{L})$ & $2.07 \pm 2.33$ & $2.27 \pm 0.44$ & $10.46 \pm 4.17^{\mathrm{a}, \mathrm{b}}$ \\
\hline
\end{tabular}

Note. Significance level was set at $\mathrm{p}<0.05$; Values expressed as mean \pm SD; ${ }^{\text {a }}$ Significantly different than pre-exercise, ${ }^{\text {b }}$ Significantly different than $1 \mathrm{~h}$ post-dose.

Table 4 illustrates the results of blood biochemical responses between $\mathrm{NaHCO}_{3}$ and placebo at the same three time points. There were no significant differences between trials in all blood responses at pre-exercise. After $1 \mathrm{~h}$ of dose con- sume, blood $\mathrm{pH}$ and $\mathrm{HCO}_{3}{ }^{-}$were higher with $\mathrm{NaHCO}_{3}$ than with placebo, but no differences were noted in lactate between trials. After the finish of the test, however, all variables were significantly higher with $\mathrm{NaHCO}_{3}$ than with placebo.

Table 4. Results of blood biochemical responses to $\mathrm{NaHCO}_{3}$ and placebo at baseline (pre-exercise), $1 \mathrm{~h}$ after ingestion, and at after exercise in 13 well-trained sprinters. Data were analysed using paired sample t test

\begin{tabular}{cccccccccc}
\hline \multirow{2}{*}{ Parameters } & \multicolumn{3}{c}{ Pre-exercise } & \multicolumn{3}{c}{1 -h post dose } & \multicolumn{3}{c}{ Post-exercise } \\
\cline { 2 - 10 }$y$ & $\mathrm{NaHCO}_{3}$ & Placebo & $\mathrm{p}$ value & $\mathrm{NaHCO}_{3}$ & Placebo & $\mathrm{p} \mathrm{value}$ & $\mathrm{NaHCO}_{3}$ & Placebo & $\mathrm{p} \mathrm{value}$ \\
\hline $\begin{array}{c}\mathrm{pH} \\
\mathrm{HCO}_{3}{ }^{-}\end{array}$ & $7.42 \pm 0.03$ & $7.43 \pm 0.02$ & 0.101 & $7.47 \pm 0.02$ & $7.43 \pm 0.02$ & $0.001^{*}$ & $7.37 \pm 0.05$ & $7.29 \pm 0.04$ & $0.001^{*}$ \\
$(\mathrm{mmol} / \mathrm{L})$ & $25.81 \pm 2.44$ & $25.74 \pm 2.74$ & 0.531 & $30.63 \pm 4.01$ & $25.59 \pm 3.22$ & $0.002^{*}$ & $17.28 \pm 4.16$ & $14.56 \pm 4.38$ & $0.021^{*}$ \\
$\begin{array}{c}\text { Lactate } \\
(\mathrm{mmol} / \mathrm{L})\end{array}$ & $1.95 \pm 1.88$ & $2.07 \pm 2.33$ & 0.281 & $2.21 \pm 0.24$ & $2.27 \pm 0.44$ & 0.347 & $13.11 \pm 3.09$ & $10.46 \pm 4.17$ & $0.043^{*}$
\end{tabular}

Note. Significance level was set at $\mathrm{p}<0.05$; Values expressed as mean $\pm \mathrm{SD}$; Significantly different from placebo.

\section{Discussion}

The primary finding of the present study was that $\mathrm{NaHCO}_{3}$ ingestion was an effective strategy to complete significantly more sprint repetitions when compared to ingestion of the placebo. This result could be explained by the excessive blood $\mathrm{HCO}_{3}{ }^{-}$concentration due to $\mathrm{NaHCO}_{3}$ consumed before the beginning of the trial, in which it enhances intracellular $\mathrm{H}^{+}$efflux. It has been documented that $\mathrm{NaHCO}_{3}$ administration can attenuate roughly $62 \%$ of the $\mathrm{H}^{+}$diffused from working muscle cells to the blood during highly intensive exercise (Carr, Webstar, Boyed, Hudson, \& Scheett, 2013; Medbo \& Tabata, 1993). Additionally, $\mathrm{NaHCO}_{3}$ can also contribute to delay the onset of fatigue by maintaining energy-producing capability (Carr et al., 2013; Requena et al., 2005) and/or by decreasing RPE (Tobias et al., 2013). Another explanation by which $\mathrm{NaHCO}_{3}$ intake increased the number of sprint repetitions during the test is that $\mathrm{NaHCO}_{3}$ could activate the actomyosin ATPase (Carr et al., 2013) and elicit a calcium release from the sarcoplasmic reticulum (Requena et al., 2005), potentiating the actomyosin coupling system, and thereby increasing muscle capacity.

The result of our study agreed with the finding of Deb et al.
(2018), who showed that exercise tolerance during an intermittent exercise test (60-s work in high-intensity to exhaustion, separated by 30 -s recovery interval) was significantly greater after $0.3 \mathrm{~g} / \mathrm{kg}$ body mass of $\mathrm{NaHCO}_{3}(845.3 \pm 242.4 \mathrm{~s})$ compared to placebo trial $(734.3 \pm 175.7 \mathrm{~s})$. However, their protocol was carried out on a cycle ergometer, and the participants were recreationally active male individuals. Another study conducted by Price et al. (2003) also demonstrated that the intake of $0.3 \mathrm{~g} / \mathrm{kg}$ of $\mathrm{NaHCO}_{3} 1 \mathrm{~h}$ prior to exercise increased peak power $(11.5 \pm 5 \%)$ expressed relative to a trial of sprint testing compared to sodium chloride (NaCL, $1.8 \pm 9.5 \%)$. In the same study, participants were nonathletes and completed an incremental cycle ergometer test which consisted of two 30-min intervals (repeated 3-min blocks; $90 \mathrm{~s}$ at $40 \% \mathrm{VO}_{2 \max }, 60 \mathrm{~s}$ at $60 \%$ $V \mathrm{O}_{2 \max }, 14$-s maximal sprint, 16-s rest). Tobias et al. (2013) reported enhanced high-intensity intermittent upper-body performance (4 30-s Wingate test, separated by $3 \mathrm{~min}$ ) following chronic beta-alanine (BA) supplementation $(6.4 \mathrm{~g} /$ day for 4 weeks) combined with $500 \mathrm{mg} / \mathrm{kg}$ of $\mathrm{NaHCO}_{3}$ ingested within seven days compared to a placebo in well-trained athletes. The total work done in that study was increased by $8 \%$ in the mode 
of $\mathrm{NaHCO}_{3}$ supplementation, which differed from our protocol. However, it has been suggested that chronic $\mathrm{NaHCO}_{3}$ can elicit muscular capacity similarly with an acute intake (Artioli et al., 2007).

Our findings were contrary to further studies. Recently, da Silva et al. (2019) showed that a combination of BA supplementation (6.4 g/day for 28 days) and acute $\mathrm{NaHCO}_{3}(0.3$ $\mathrm{g} / \mathrm{kg}$ ) $60 \mathrm{~min}$ prior to cycling time-trial (60-s bouts at $110 \%$ of maximal power output, separated by 60 -s rest) did not improve performance compared to each one alone and placebo in male cyclists. However, they suggested that $\mathrm{NaHCO}_{3}$ increased the estimated glycolytic ATP-PCr systems. de Salles Painelli et al. (2013) reported that $0.3 \mathrm{~g} / \mathrm{kg}$ of $\mathrm{NaHCO}_{3}$ intake following BA supplementation (3.2-6.4 g/day for 4 weeks) had no egrogenic effect in 100- and 200-m swimming performance in swimmers. A limitation of that study was the lack of blood $\mathrm{HCO}_{3}-$ measurement, so they failed to suggest an explanation for non-significant performance improvement. de Araujo Dias et al. (2015) observed that the ingestion of $0.3 \mathrm{~g} / \mathrm{kg}$ of $\mathrm{NaHCO}_{3}$ did not affect graded high-intensity cycling capacity test which initiated at $100 \mathrm{~W}$ and increased by $6 \mathrm{~W}$ every 15 $s$ until volitional exhaustion compared to placebo. The explanation of their finding was attributed to a variability of monocarboxylate (MCT) transporter protein activity after $\mathrm{NaHCO}_{3}$ intake and to $\mathrm{H}^{+}$efflux ratio from myocytes into blood. However, participants recruited in that study were recreationally active individuals. In addition, conflicting findings have been observed when the duration of an exercise lasting less than 2 min (Requena et al., 2005). Danaher et al. (2014) showed no differences in repeated sprint ability (RSA) test (5 repeats of 6 $\mathrm{s}$ maximal effort cycling bouts, separated by $24 \mathrm{~s}$ rest) between $\mathrm{NaHCO}_{3}(300 \mathrm{mg} / \mathrm{kg}), \mathrm{BA}$ (4.8-6.4 g/day for 4 weeks) and placebo trials. However, time-to-exhaustion during cycling capacity test performed following RSA was increased $16 \%$ with a combination of $\mathrm{NaHCO}_{3}+\mathrm{BA}$. The lack of ergogenic effect of $\mathrm{NaHCO}_{3}$ intake upon performance in previous studies might be associated with the type of exercise protocol, the duration of exercise, the small number of the sample, the intensity of exercise, and the environmental temperatures.

Our results showed that blood $\mathrm{pH}$ and $\mathrm{HCO}_{3}{ }^{-}$were significantly higher after the finish of the test in the $\mathrm{NaHCO}_{3}$ trial than that of the placebo trial, which might indicate the effective buffering capacity of the extracellular median due to $\mathrm{NaHCO}_{3}$ intake. Increased extracellular $\mathrm{pH}$ and raised $\mathrm{HCO}_{3}{ }^{-}$due to $\mathrm{NaHCO}_{3}$ consume might raise the $\mathrm{H}^{+}$and lactate efflux from working muscles (Requena et al., 2005) by increasing the activity of the lactate- $/ \mathrm{H}^{+}$cotransporter. This mechanism delays the drop in $\mathrm{pH}$ (Marx et al., 2002), delays the onset of fatigue (Hobson, et al., 2013), and leads to higher contractile force (McNaughton et al., 1999) by sustained muscle glycolytic ATP production (McKenzie, Couts, Stirling, Hoeben, \& Kubara, 1986; Kemp \& Foe, 1983). In this context, however, increased activation of glycolytic ATP-PCr systems induce high lactate levels (da Silva et al., 2019). Increased post-exercise lactate has been reported after $\mathrm{NaHCO}_{3}$ intake (da Silva et al., 2019; Bishop et al., 2004), which might explain the elevated blood lactate after the finish of the test in the $\mathrm{NaHCO}_{3}$ trial compared to the placebo in the present study. Additionally, the greater sprints repetitions as a result of $\mathrm{NaHCO}_{3}$ consume was also contributed to elevation in blood lactate levels. In a study conducted by Deb et al. (2018), blood $\mathrm{HCO}_{3}{ }^{-}$was significantly higher in experimental trial after intermittent testing $(16.0 \pm 2.0 \mathrm{mmol} / \mathrm{L})$ compared to $13.0 \pm 3.0 \mathrm{mmol} / \mathrm{L}$ in a placebo trial, and blood $\mathrm{pH}$ was decreased from 7.47 (pre-test) to 7.31 (post-test) in $\mathrm{NaHCO}_{3}$ trial compared to placebo $(7.39 ; 7.20$, respectively). In the same study, however, post-test blood lactate was significantly elevated in $\mathrm{NaHCO}_{3}$ trial $(17.9 \pm 5.9 \mathrm{mmol} / \mathrm{L})$ compared to a placebo $(13.9 \pm 4.3 \mathrm{mmol} / \mathrm{L})$. da Silva et al. (2019) found that blood lactate (15.7 mmol/L), $\mathrm{pH}$ (7.30), and $\mathrm{HCO}_{3}{ }^{-}(22.1$ $\mathrm{mmol} / \mathrm{L})$ were significantly changed after exercise compared to placebo $(12.0 \mathrm{mmol} / \mathrm{L} ; 7.25 ; 19.5 \mathrm{mmol} / \mathrm{l}$, respectively). Hobson et al. (2013) showed that chronic BA ( $6.4 \mathrm{~g} /$ day for 4 weeks) followed by acute $\mathrm{NaHCO}_{3}(0.2 \mathrm{~g} / \mathrm{kg})$ were likely to be beneficial to $2.000-\mathrm{m}$ rowing performance, with increased post-exercise blood $\mathrm{pH}, \mathrm{HCO}_{3}{ }^{-}$and lactate compared to placebo group in rowers.

\section{Conclusion}

It can be concluded from the present data that acute (single dose) sodium bicarbonate can attenuate acidosis during high-intensity intermittent exercise and improve performance following intake $0.3 \mathrm{~g} / \mathrm{kg}$ orally in well-trained sprinters, which indicates that sodium bicarbonate may act as a physicochemical buffer in the body and may represent, in part, an explanation for the ergogenic effect in sprint-intermittent exercise. Additionally, these data confirm that post-exercise blood lactate increases after the consumption of sodium bicarbonate.

\section{Acknowledgements}

We are indebted to the Nutritionist N. Asi for the supplements used in this study, as well as the coaches who assisted as examiners. We also thank R. Dbaei for consultant of statistical analysis and athletes for volunteering their effort and time.

\section{References}

Artioli, G.G., Gualano, B., Coelho, D.F., Benatti, F.B., Gailey, A.W., \& Lancha Jr, A.H. (2007). Does sodium-bicarbonate ingestion improve simulated judo performance? International Journal of Sport Nutrition and Exercise Metabolism, 17, 206-217. doi: 10.1123/ijsnem.17.2.206

Bishop, D., Edge, J., Davis, C., \& Goodman, C. (2004). Induced metabolic alkalosis affects muscle metabolism and repeated sprint ability. Medicine \& Science in Sports \& Exercise, 36, 807-813. doi: 10.1249/01.MSS.0000126392.20025.17

Carr, A.J., Slater, G.J., Gore, C.J., Dawson, B., \& Burke, L.M. (2011). Effect of sodium bicarbonate on $\left[\mathrm{HCO}_{3}{ }^{-}\right], \mathrm{pH}$, and gastrointestinal symptoms. International Journal of Nutrition and Exercise Metabolism, 21, 189-194. doi: 10.1123/ijsnem.21.3.189

Carr, B.M., Webstar, M.J., Boyed, J.C., Hudson, G.M., \& Scheett, T.P. (2013). Sodium bicarbonate supplementation improves hypertrophy-type resistance exercise performance. European Journal of Applied Physiology, 113, 743-752. doi: 10.1007/s00421-012-2484-8

Coso, J.D., Hamouti, N., Agudo-Jimenez, R., \& MoraRodriguez, R. (2010). Restoration of blood pH between repeated bouts of high-intensity exercise: effects of various active-recovery protocols. European Journal of Applied Physiology, 108, 523-532. doi: 10.1007/s00421-009-1248-6

da Silva, R.P., de Oliveira, L.F., Saunders, B., de Andrade Kratz, C., de Salles Painelli, V., da Eira Silva, V., Marins, J.C.B., Franchini, E., Gualano, B., \& Artioli, G.G. (2019). Effects of $\beta$-alanine and sodium bicarbonate supplementation on 
the estimated energy system contribution during highintensity intermittent exercise. Amino Acids, 51, 83-96. doi: 10.1007/s00421-014-2895-9

Danaher, J., Gerber, T., Wellard, B.M., \& Stathis, C.G. (2014). The effect of $\beta$-alanine and $\mathrm{NaHCO}_{3}$ co-ingestion on buffering capacity and exercise performance with highintensity exercise in healthy males. European Journal of Applied Physiology, 114, 1715-1724. doi: 10.1007/s00421014-2895-9

de Araujo Dias, G.F., da Eira Silva, V., de Salles Painelli, V., Sale, C., Artioli, G.G., Gualano, B., \& Saunders, B. (2015). (In) Consistencies in responses to sodium bicarbonate supplementation: a randomised, repeated measures, counterbalanced and double-blind study. PLOS ONE, 10(11), 1-13. doi: 10.1371/journal.pone.0143086

de Salles Painelli, V., Roschel, H., de Jesus, F., Sale, C., Harris, R.C., Solis, M.Y., Benatti, F.B., Gualano, B., Lancha Jr, A.H., \& Artioli, G.G. (2013). The ergogenic effect of beta-alanine combined with sodium bicarbonate on high-intensity swimming performance. Applied Physiology Nutrition and Metabolism, 38, 525-532. doi: 10.1139/apnm-2012-0286

Deb, S.K., Gough, L.A., Sparks, S.A., \& McNaughton, L.R. (2018). Sodium bicarbonate supplementation improves severe-intensity intermittent exercise under moderate acute hypoxia conditions. European Journal of Applied Physiology, 118, 607-615. doi: 10.1007/s00421-018-3801-7

Debold, E.P., Fitts, R.H., Sundberg, C.W., \& Nosek, T.M. (2016). Muscle fatigue from the perspective of a single crossbridge. Medicine \& Science in Sports \& Exercise, 11, 2270-2280. doi: 10.1249/MSS.0000000000001047

Fitts, R.H. (2016). The role of acidosis in fatigue: pro perspective. Medicine \& Science in Sports \& Exercise, 11, 2335-2338. doi: 10.1249/MSS.0000000000001043

Gladden, L.B. (2004). Lactate metabolism: a new paradigm for the third millennium. The Journal of Physiology, 558, 5-30. doi: 10.1113/jphysiol.2003.058701

Hobson, R.M., Harris, R.C., Martin, D., Smith, P., Macklin, B., Gualano, B., \& Sale, C. (2013). Effect of $\beta$-alanine with and without sodium bicarbonate on 2.000-m rowing performance. International Journal of Sport Nutrition and Exercise Metabolism, 23, 480-487. doi: 10.1123/ ijsnem.23.5.480

Hobson, R.M., Saunders, B., Ball, G., Harris, R.C., \& Sale, C. (2012). Effects of $\beta$-alanine supplementation on exercise performance: a meta-analysis. Amino Acids, 43, 25-37. doi: 10.1007/s00726-011-1200-z

Kemp, R.J., \& Foe, L.G. (1983). Allosteric regulatory properties of muscle phosphofructokinase. Molecular and Cellular Biochemistry, 57, 147-154. doi: 10.1007/BF00849191

Lancha Junior, A.H., de Salles Painelli, V., Saunders, B., \& Artioli, G.G. (2015). Nutritional strategies to modulate intracellular and extracellular buffering capacity during high-intensity exercise. Sports Medicine, 45(Suppl 1), S71-S81. doi: 10.1007/s40279-015-0397-5

Marx, J.O., Gordon, S.E., Vos, N.K., Nindl, B.C., Gomez, A.L., Volekk, J.S., Pedro, J., Ratamess, N., Newton, R.U., French,
D.N., Rubin, M.R., Hakkinen, K., \& Kraemer, W.J. (2002). Effect of alkalosis on plasma epinephrine responses to high intensity cycle exercise in humans. European Journal of Applied Physiology, 87, 72-77. doi: 10.1007/s00421-0020591-7

McKenzie, D.C., Couts, K.D., Stirling, D.R., Hoeben, H.H., \& Kubara, G. (1986). Maximal work production following two levels of artificially induced metabolic alkalosis. Journal of Sports Sciences, 4, 35-38. doi: 10.1080/02640418608732096

McNaughton, L., Backx, K., Palmer, G., \& Strange, N. (1999). Effects of chronic bicarbonate ingestion on the performance of high-intensity work. European Journal of Applied Physiology, 80, 333-336. doi: 10.1007/s004210050600

Medbo, J.I., \& Tabata, I. (1993). Anaerobic energy release in working muscle during $30 \mathrm{~s}$ to $3 \mathrm{~min}$ of exhausting bicycling. Journal of Applied Physiology, 75(4), 16541660. doi: 10.1152/jappl.1993.75.4.1654

Oliveira, L.F., de Salles Painelli, V., Nemezio, K., Goncalves, L.S., Yamaguchi, G., Saunders, B., Gualano, B., \& Artioli, G.G. (2017). Chronic lactate supplementation does not improve blood buffering capacity and repeated highintensity exercise. Scandinavian Journal of Medicine and Science in Sports, 27, 1231-1239. doi: 10.1111/sms.12792

Price, M., Moss, P., \& Prance, S. (2003). Effects of sodium bicarbonate ingestion on prolonged intermittent exercise. Medicine \& Science in Sports \& Exercise, 35(8), 1303-1308. doi: 10.1249/01.MSS.0000079067.46555.3C

Requena, B., Zabala, M., Padial, P., \& Feriche, B. (2005). Sodium bicarbonate and sodium citrate: ergogenic aids?. The Journal of Strength and Conditioning Research, 19(1), 213-224.

Robergs, R., Hutchinson, K., Hendee, S., Madden, S., \& Siegler, J. (2005). Influence of pre-exercise acidosis and alkalosis on the kinetics of acid-base recovery following intense exercise. International Journal of Sport Nutrition and Exercise Metabolism, 15, 59-74. doi: 10.1123/ijsnem.15.1.59

Sahlin, K., Harris, R.C., \& Hultman, E. (1975). Creatine kinase equilibrium and lactate content compared with muscle $\mathrm{pH}$ in tissue samples obtained after isometric exercise. Biochemical Journal, 152, 173-180. doi: 10.1042/bj1520173

Saunders, B., Elliott-Sale, K., Artioli, G.G., Swinton, P.A., Dolan, E., Roschel, H., Sale, C., \& Gualano, B. (2017). $\beta$-Alanine supplementation to improve exercise capacity and performance: a systemic review and meta-analysis. British Journal of Sports Medicine, 51, 658-669. doi: 10.1136/bjsports-2016-096396

Sweeney, K.M., Wright, G.A., Brice, A.G., \& Doberstein, S.T. (2010). The effect of $\beta$-alanine supplementation on power performance during repeated sprint activity. Journal of Strength and Conditioning Research, 24, 79-87. doi: 10.1519/JSC.0b013e3181c63bd5

Tobias, G., Benatti, F.B., de Salles Painelli, V., Roschel, H., Gualano, B., Sale, C., Harris, R.C., Lancha Jr, A.H., \& Artioli, G.G. (2013). Additive effects of beta-alanine and sodium bicarbonate on upper-body intermittent performance. Amino Acids, 45, 309-317. doi: 87.236.233.3 